\section{Reply to, "RET Germline Mutations in Codon 609 and MEN2A Phenotype: Are They All Created Equal?" by Machens and Dralle (ASO-2009-06-0652)}

\section{TO THE EDITORS:}

We thank Drs. Machens and Dralle for reviewing our paper so thoroughly and pointing out some potential problems with our Table 3. Specifically, they have raised the question of whether there could have been overlap in some of the studies we included that reported C609G and C609S RET mutations. It does appear plausible that three of the five reports of C609S mutations could have overlap, as they all originate from Semmelweis University in Budapest. ${ }^{1-3}$ Although there are discrepancies between these three reports, such as the age of one affected person with pheochromocytoma, and whether there are two or three family members with medullary thyroid cancer (MTC), it seems reasonable to suspect that these studies are discussing the same family. Combining this C609S family with that described by Kinlaw et al. and the recent report by Mian et al., 6/29 (21\%) affected family members had pheochromocytoma, and the youngest case of MTC was found at an age of 17 years. ${ }^{4,5}$

Similarly, the reports of two families described with C609G RET mutations by Simon et al. and Fitze et al. both share one author from Erlangen, and their pedigrees are similar enough to suggest they also represent a single family. ${ }^{6,7}$ We therefore agree that the numbers represented in our Table 3 for C609S and C609G mutations overestimate the prevalence of pheochromocytoma in families with these mutations. However, this prevalence is still higher than for any other mutations in RET codon 609, and the youngest ages of the diagnosis of MTC were also earlier (age 5 years for $\mathrm{C} 609 \mathrm{G}$ and 17 years for C609S). The evidence therefore supports our original conclusion that
C609G and C609S mutations are associated with more aggressive disease.

Daniel Calva, $\mathrm{MD}^{1}$, Thomas O'Dorisio, $\mathrm{MD}^{3}$, M. Sue O'Dorisio, MD, $\mathbf{P h D}^{2}$, Geeta Lal, $\mathrm{MD}^{1}$, Sonia Sugg, $\mathrm{MD}^{1}$, Ronald Weigel, $\mathrm{MD}, \mathrm{PhD}^{\mathbf{1}}$, and James Howe, $\mathrm{MD}^{1}$

${ }^{1}$ Department of Surgery, University of Iowa Carver College of Medicine, Iowa City, IA;

${ }^{2}$ Department of Pediatrics, University of Iowa Carver College of Medicine, Iowa City, IA;

${ }^{3}$ Department of Internal Medicine, University of Iowa

Carver College of Medicine, Iowa City, IA

e-mail: james-howe@uiowa.edu

Published Online: 14 October 2009

(C) Society of Surgical Oncology 2009

\section{REFERENCES}

1. Klein I, Esik O, Homolya V, Szeri F, Váradi A. Molecular genetic diagnostic program of multiple endocrine neoplasia type $2 \mathrm{~A}$ and familial medullary thyroid carcinoma syndromes in Hungary. J Endocrinol. 2001;170:661-6.

2. Igaz P, Patócs A, Rácz K, Klein I, Váradi A, Esik O. Occurrence of pheochromocytoma in a MEN2A family with codon 609 mutation of the RET proto-oncogene. J Clin Endocrinol Metab. 2002;87: 1994.

3. Patócs A, Karádi E, Tóth M, Varga I, Szücs N, Balogh K, et al. Clinical and biochemical features of sporadic and hereditary pheochromocytomas: an analysis of 41 cases investigated in a single endocrine centre. Eur J Cancer Prev. 2004;13:403-9.

4. Kinlaw WB, Scott SM, Maue RA, et al. Multiple endocrine neoplasia 2A due to a unique C609S RET mutation presents with pheochromocytoma and reduced penetrance of medullary thyroid carcinoma. Clin Endocrinol (Oxf). 2005;63:676-82.

5. Mian C, Barollo S, Zambonin L, Pennelli G, Bernante P, Pelizzo MR, et al. Characterization of the largest kindred with MEN2A due to a Cys609Ser RET mutation. Fam Cancer. (doi:10.1007/ s10689-009-9250-z; e-pub ahead of print 28 May 2009).

6. Simon S, Pavel M, Hensen J, Berg J, Hummer HP, Carbon R. Multiple endocrine neoplasia 2A syndrome: surgical management. J Pediatr Surg. 2002;37:897-900.

7. Fitze G, Schreiber M, Hohenberger W, Hümmer HP, Roesner D, Schackert HK. Interaction of RET proto-oncogene codon 609 mutations with RET haplotypes characterized by c.135G $>$ A alleles modifying MEN 2A or HSCR phenotypes. Am J Med Genet A. 2004;129A:323-5. 